\title{
FORMAÇÃO DO POMAR DE TANGERINEIRA 'PONCÃ', EM FUNÇÃO DA ADUBAÇÃO QUÍMICA E ORGÂNICA ${ }^{1}$
}

\author{
TATIANA REZENDE PIRES DE ALMEIDA², SARITA LEONEL ${ }^{3}$, MARCO ANTONIO TECCHIO4, \\ MARTHA MARIA MISCHAN ${ }^{5}$
}

\begin{abstract}
RESUMO - Avaliou-se o efeito do esterco de curral curtido na adubação de formação do pomar de tangerineira 'Poncã' (Citrus reticulata, Blanco), comparando com a adubação química convencional. O experimento foi conduzido na Fazenda Experimental São Manuel da Faculdade de Ciências Agronômicas da UNESP, Câmpus de Botucatu-SP. Os tratamentos foram aplicados na adubação de formação do pomar durante dois anos. No primeiro ano, utilizaram-se 7,5;15,0;22,5 e 30,0 kg planta ${ }^{-1}$ de esterco de curral curtido e $400 \mathrm{~g}_{\text {planta }}{ }^{-1}$ de sulfato de amônio. Na adubação de formação do segundo ano, as doses de esterco de curral foram 15,0; 22,5; 30,0 e 37,5 kg planta ${ }^{-1}$ e 800 g planta $^{-1}$ de sulfato de amônio. Nos dois anos, a adubação foi parcelada em três aplicações. Realizaram-se as avaliações aos 30; 150 e 270 dias após a última parcela de adubação do segundo ano, determinando-se: altura da planta, diâmetro do caule, volume, projeção e circunferência da copa. O delineamento experimental foi inteiramente casualizado, em parcelas subdivididas no tempo, e 3 repetições, sendo as parcelas representadas pela adubação e as subparcelas pelas épocas de avaliação. Verificou-se que, na média das avaliações, houve aumento linear das características avaliadas com o incremento das doses de esterco de curral curtido. Não houve diferença significativa entre os tratamentos com adubo orgânico e químico.
\end{abstract}

Termos para indexação: Citrus reticulata, tangerineira 'Poncã', esterco.

\section{DEVELOPMENT OF 'PONCÃ' MANDARIN ORCHARD WITH CHEMICAL AND ORGANIC FERTILIZATION}

ABSTRACT - The effects of chemical and organic fertilization were studied on growth of 'Poncã' mandarin orchard. The organic fertilization was made with manure during two years at the 'Poncã' mandarin orchard formation (1-2 year old). In the first year the manure levels that were put were as follow: $7.5 ; 15.0 ; 22.5$ and $30.0 \mathrm{Kg}$ per plant and $400 \mathrm{~g}$ of ammonium sulfate per plant. In the second year the manure levels were: $15.0 ; 22.5 ; 30.0$ and $37.5 \mathrm{Kg}$ per plant and $800 \mathrm{~g}$ of ammonium sulfate per plant. During the two years the fertilization were put in three applications. The parameters evaluated were: plants height, stem diameter, volume, projection and circumference of plant. The experiment was entirely randomized with split plots in time and 3 replications. The plots were the fertilization systems and the subplots were the evaluation time. The manure applications enhanced the plants growth. The chemical and organic fertilization showed the same growth on the 'Poncã' mandarin formation orchard.

Index terms: Citrus reticulata, 'Poncã' mandarin, manure.

\section{INTRODUÇÃO}

O Brasil é o maior produtor mundial de citros, tendo destaque a citricultura paulista com uma área de aproximadamente 830 mil hectares. As tangerinas constituem o segundo grupo de frutos mais importantes da citricultura, sendo o Brasil o quarto produtor mundial com uma área de 27 mil hectares, onde a produção da tangerina 'Poncã' representa $50 \%$ da produção nacional (Agrianual, 2004).

De acordo com Silva et al. (1996), a matéria orgânica é responsável pela manutenção da vida do solo, com benefícios observados nas propriedades físicas, químicas, físico-químicas e biológicas do mesmo. Segundo Kiehl (1985), diversos trabalhos publicados sobre a utilização de matéria orgânica de diferentes fontes demonstraram o alto valor desse material como fertilizante, corretivo e condicionador do solo.

A utilização da matéria orgânica em pomares cítricos traz inúmeros benefícios ao crescimento e desenvolvimento das plantas e às propriedades do solo. Para a citricultura, sabe-se que a utilização da matéria orgânica é importante na manutenção da fertilidade do solo e na produtividade, porém, trabalhos que recomendem as melhores fontes, doses, épocas e modo de aplicação, são escassos.

Cunha Sobrinho et al. (1975), avaliando o efeito da adubação mineral comparada com a adubação orgânica em mudas de laranjeira 'Natal', enxertada em limoeiro 'Cravo', concluíram que, no primeiro ano e aos 21 meses após o plantio, não houve diferenças significativas no diâmetro do tronco, circunferência da copa e altura da planta.

Jones et al. (1961), citados por Malavolta e Violante Netto (1989), verificaram que, com a aplicação de esterco de curral, ocorreu aumento da penetração de água de irrigação, tendo correlação positiva entre esse fator e a produção. Boeira et al. (1986) compararam o efeito da adubação mineral e orgânica no crescimento dos porta-enxertos de limoeiro 'Cravo', laranjeira 'Caipira' e Poncirus trifoliata cv. Taquari, até a repicagem. Constataram que, apenas na laranjeira 'Caipira', a adubação mineral e a adubação com casca de acácia-negra propiciaram maior desenvolvimento.

De acordo com Kiehl (1985), a matéria seca do esterco de curral deve conter: $17 \mathrm{~g} \mathrm{~kg}^{-1}$ de N; $7 \mathrm{~g} \mathrm{~kg}^{-1}$ de $\mathrm{P}_{2} \mathrm{O}_{5} ; 27 \mathrm{~g} \mathrm{~kg}^{-1}$ de k 2 O $12 \mathrm{~g} \mathrm{~kg}^{-1} \mathrm{de}$ $\mathrm{Ca} ; 6,1 \mathrm{~g} \mathrm{~kg}^{-1} \mathrm{de} \mathrm{Mg} ; 31 \mathrm{mg} \mathrm{kg}^{-1} \mathrm{de} \mathrm{Cu} ; 4106 \mathrm{mg} \mathrm{kg}^{-1} \mathrm{de} \mathrm{Fe} ; 510 \mathrm{mg} \mathrm{kg}^{-1} \mathrm{de}$ $\mathrm{Mn} ; 64 \mathrm{mg} \mathrm{kg}^{-1}$ de Zn e relação C/N de 32/1. Segundo Silva et al. (1996), a composição do esterco é bastante variável, dependendo da espécie, idade do animal, alimentação, do material utilizado na cama e dos métodos de preparação do curtimento.

Dentre os nutrientes minerais fornecidos pela matéria orgânica, o nitrogênio, que se encontra em maior quantidade, é um dos elementos mais importantes para a citricultura. Há fortes evidências de que a intensidade do florescimento e, conseqüentemente, a produção dependem de carboidratos presentes nas plantas e, principalmente, do conteúdo foliar de N (Lovatt et al., 1992, citado por Panzenhagen et al., 1999). Segundo Malavolta \& Violante Netto (1989), o efeito do nitrogênio na produção é marcante, porém sem eficácia na qualidade dos frutos.

Internacionalmente, os produtos orgânicos têm uma demanda ascendente no mercado externo, conseguindo melhores preços que os convencionais (Carmo et al., 1996). Outro aspecto positivo, em relação aos produtos orgânicos, é a criação de selos de certificação de qualidade por parte de organizações não-governamentais, o que garante ao produtor uma agregação de valor. Do ponto de vista técnico e científico,

\footnotetext{
${ }^{1}$ (Trabalho 185/2004). Recebido: 05/11/2004. Aceito para publicação: 05/08/2005.

${ }^{2}$ Aluna graduanda em Agronomia- Faculdade de Ciências Agronômicas, Caixa Postal 237 - 18603-970 Botucatu - SP. Correio eletrônico: trpdalmeida@fca.unesp.br.

${ }^{3}$ Professora do Departamento de Produção Vegetal/ área Horticultura da UNESP - Faculdade de Ciências Agronômicas, Caixa Postal 237 - $18603-970$ BotucatuSP. Correio eletrônico: sarinel@fca.unesp.br.

${ }^{4}$ Doutorando do Departamento de Produção Vegetal/ área Horticultura da UNESP - Faculdade de Ciências Agronômicas, Caixa Postal 237 - $18603-970$ BotucatuSP. Correio eletrônico: marcotecchio@fca.unesp.br.

${ }^{5}$ Professora do Instituto de Biociências. Departamento de Bioestatística UNESP.
} 
TABELA 1 - Análises químicas do Latossolo Vermelho-Amarelo distrófico. FCA/UNESP, Botucatu-SP, 2004.

\begin{tabular}{|c|c|c|c|c|c|c|c|c|c|c|c|c|c|}
\hline $\begin{array}{c}\mathrm{pH} \\
\mathrm{CaCl}_{2}\end{array}$ & $\begin{array}{l}\text { M.O. } \\
\text { g.dm }{ }^{-3}\end{array}$ & $\begin{array}{l}\text { Presina } \\
\mathrm{mg} \mathrm{dm}^{-3}\end{array}$ & $\mathrm{H}+\mathrm{Al}$ & $\mathrm{K}$ & $\begin{array}{c}\mathrm{Ca} \\
\mathrm{mol}\end{array}$ & $\mathrm{Mg}$ & CTC & $\begin{array}{l}\mathrm{V} \\
\%\end{array}$ & B & $\mathrm{Cu}$ & $\begin{array}{l}\mathrm{Fe} \\
\mathrm{mg}\end{array}$ & $\mathrm{Mn}$ & $\mathrm{Zn}$ \\
\hline \multicolumn{14}{|c|}{ A - julho 2001} \\
\hline 5,9 & 7 & 8 & 15 & 0,9 & 13 & 5 & 34 & 56 & 0,14 & 0,3 & 11 & 5,4 & 0,4 \\
\hline \multicolumn{14}{|c|}{ B - janeiro 2002} \\
\hline 5,8 & 9 & 7 & 10 & 0,9 & 20 & 9 & 39 & 75 & 0,13 & 0,4 & 9 & 6,8 & 0,3 \\
\hline
\end{tabular}

os desafios que a agricultura orgânica impõe são imensos. Nesse sentido, Bonilla (1992) afirma que é necessária muita pesquisa para o desenvolvimento de tecnologias adequadas e operacionais para aumentar a produtividade das culturas em manejo orgânico.

Poucos são os trabalhos relacionados com a adubação de formação de pomares cítricos, principalmente quando se trata de adubação orgânica. Portanto, o experimento teve por finalidade avaliar os efeitos do esterco de curral curtido na adubação de formação do pomar de tangerineira 'Poncã' (Citrus reticulata Blanco) e compará-los com a adubação química convencional, recomendada pelo Grupo Paulista de Calagem e Adubação dos Citros.

\section{MATERIAL E MÉTODOS}

O trabalho foi conduzido na Fazenda Experimental São Manuel da Faculdade de Ciências Agronômicas da UNESP, Câmpus de BotucatuSP, localizada a $22^{\circ} 44^{\prime}$ S., $48^{\circ} 34^{\prime} \mathrm{O}$., e altitude de $740 \mathrm{~m}$. O clima, segundo Tubelis \& Salibe (1989), é classificado como Cfa, e o solo, de acordo com Carvalho et al.(1983), é caracterizado como Latossolo VermelhoAmarelo distrófico (Prado, 2003).

As mudas de tangerineira 'Poncã' (Citrus reticulata, Blanco), enxertadas em Citrumelo 'Swingle', foram obtidas em um viveiro comercial localizado em Conchal-SP.

A área destinada ao plantio das mudas foi previamente arada e gradeada, sendo realizada posteriormente a correção da acidez com calcário dolomítico, de acordo com o resultado da análise de solo (Tabela $1-\mathrm{A})$, visando a elevar a saturação por bases a 70\%. A adubação para o plantio seguiu as recomendações de De Negri (1997), sendo incorporados nas covas de plantio, com antecedência de 40 dias: 10 litros de esterco de curral curtido, $1 \mathrm{~kg}$ de termofosfato com boro e zinco, $500 \mathrm{~g}$ de calcário dolomítico e $200 \mathrm{~g}$ de cloreto de potássio.

Realizou-se o plantio das mudas em dezembro de 2001, no espaçamento $6 \times 4 \mathrm{~m}$. Após o pegamento das mudas, aos 40 dias após o plantio, seguindo recomendação de adubação de Quaggio et al. (1996), teve início a aplicação dos tratamentos, com base nos resultados da análise de solo realizada em janeiro de 2002 (Tabela 1-B). De acordo com esta recomendação, as doses de nitrogênio para a adubação em cobertura foram de 80 e $160 \mathrm{~g}_{\text {planta }}^{-1}$, respectivamente no primeiro e segundo anos de formação das mudas. Nos dois anos de formação das mudas, o tratamento-testemunha foi o sulfato de amônio na dose recomendada, e os outros tratamentos, com esterco de curral curtido. O tratamento T3, equivalente a 15 e $22,5 \mathrm{~kg}_{\text {planta }}{ }^{-1}$ de esterco de curral, respectivamente no $1^{\circ}$ e $2^{\circ}$ anos, representou a dose equivalente de nitrogênio à do sulfato de amônio. A descrição dos tratamentos empregados encontrase na Tabela 2.

$\mathrm{Na}$ adubação de formação do $1^{\circ}$ ano, os adubos foram

TABELA 2 - Tratamentos utilizados na adubação de formação do $1^{\circ}$ e $2^{\circ}$ anos em pomar de tangerineira Poncã. FCA/UNESP, Botucatu-SP, 2004.

\begin{tabular}{lcc}
\hline \multicolumn{1}{c}{ Tratamentos } & \multicolumn{2}{c}{ Dose de adubo planta $^{-1}(\mathrm{~kg})$} \\
\hline & $1^{\mathbf{0}}$ ano & $2^{\mathrm{o}}$ ano \\
\hline 1 - Sulfato de amônio & 0,4 & 0,8 \\
- Esterco de curral & 7,5 & 15,0 \\
3 - Esterco de curral & 15,0 & 22,5 \\
4 - Esterco de curral & 22,5 & 30,0 \\
5 - Esterco de curral & 30,0 & 37,5 \\
\hline
\end{tabular}

distribuídos em cobertura, em uma faixa de $0,5 \mathrm{~m}$ ao redor do tronco, sendo as aplicações realizadas nos meses de janeiro, fevereiro e março de 2002.

Na adubação de formação do $2^{\circ}$ ano, em função dos resultados da análise de solo realizada no mês de dezembro de 2002, utilizou-se adicionalmente, para todos os tratamentos, como fonte de fósforo e de potássio, respectivamente, de $500 \mathrm{~g}$ de superfosfato simples planta ${ }^{-1} \mathrm{e}$ $100 \mathrm{~g}$ de cloreto de potássio planta ${ }^{-1}$. A adubação foi feita em cobertura, em faixas de $1,5 \mathrm{~m}$ ao redor do tronco da planta, sendo parcelada nos meses de fevereiro, março e abril de 2003.

As avaliações para verificar o crescimento das plantas foram realizadas nos meses de maio e setembro de 2003 e janeiro de 2004, correspondendo a, respectivamente, $30 ; 150$ e 270 dias após a última parcela de adubação de formação do $2^{\circ}$ ano. Analisaram-se as seguintes características:

Altura da planta - em cm, medido com régua de madeira graduada;

Diâmetro médio do caule $-\mathrm{em} \mathrm{cm}$, medido com paquímetro a $30 \mathrm{~cm}$ do solo;

Circunferência da copa- $\mathrm{C}=\pi \cdot \mathrm{R}^{2} \quad \mathrm{C}=$ circunferência $(\mathrm{cm}) ; \mathrm{R}=$ raio da copa $(\mathrm{cm})$;

Volume da copa $-\mathrm{V}=2 / 3 \pi$.H. $\mathrm{R}^{2} \quad \mathrm{~V}=$ volume da copa $\left(\mathrm{m}^{3}\right) ; \mathrm{H}=$ altura da planta $(\mathrm{m}) ; \mathrm{R}=$ raio da copa $(\mathrm{m})$;

Projeção da copa $-\mathrm{em} \mathrm{m}^{2}$, de acordo com Mourão Filho (1989):

$\mathrm{P}=\pi \cdot \mathrm{R}^{2}$

$\mathrm{P}=$ área de projeção da copa $\left(\mathrm{m}^{2}\right) ; \mathrm{R}=$ raio da $\operatorname{copa}(\mathrm{m})$.

Utilizou-se do delineamento experimental inteiramente casualizado, com 3 repetições, em parcelas subdivididas no tempo, sendo as adubações aplicadas às parcelas e as três épocas de avaliações aplicadas às subparcelas. Cada parcela foi constituída de 3 plantas. Utilizando o programa SAS (Statistical Analysis System), realizaram-se a análise de variância e a regressão polinomial em cada época de avaliação e na média das três épocas, para verificar a influência das doses de esterco de curral nas características avaliadas. Para comparar o efeito das adubações orgânicas com a adubação química, realizou-se o teste $t$ de Dunnett, ao nível de 5\%. O quadro de análise de variância do experimento é mostrado na Tabela 3.

TABELA 3 - Análise de variância do experimento com parcelas subdivididas no tempo. FCA/UNESP, Botucatu-SP, 2004.

\begin{tabular}{cc}
\hline Causas de variação & GL \\
\hline ADUBAÇ̃̃O & 4 \\
Erro (A) & 10 \\
ÉPOCA & 2 \\
Erro (B) & 4 \\
Interação (A*B) & 8 \\
Erro (C) & 16 \\
Total & 44 \\
\hline
\end{tabular}

\section{RESULTADOS E DISCUSSÃO}

Verificou-se que o resultado da análise química do solo, realizada em janeiro de 2002 (Tabela 1-B), apresentou menor acidez potencial e maior teor de cálcio, magnésio e de saturação por bases, quando comparado com o resultado da análise realizada em julho de 2001 (Tabela 1-A). Isso ocorreu em função da calagem realizada antes da instalação do pomar.

Os resultados do teste $\mathrm{F}$ da análise de variância das características avaliadas são apresentados na Tabela 4. Verificou-se que, para todas as características consideradas, somente o fator época 
TABELA 4 - Resultados do teste F da análise de variância da altura da planta,diâmetro do caule, projeção, volume e circunferência da copa de tangerineira 'Poncã' submetida a diferentes tratamentos com adubo químico e orgânico, em 3 épocas de avaliação. FCA/UNESP, Botucatu-SP, 2004.

\begin{tabular}{ccccccc}
\hline Causas de Variação & GL & Altura da planta & Diâmetro do caule & Projeção da copa & Volume da copa & Circunferência da copa \\
\hline Adubação (A) & 4 & $2.18^{\mathrm{NS}}$ & $1,80^{\mathrm{NS}}$ & $1,81^{\mathrm{NS}}$ & $1,83^{\mathrm{NS}}$ & $2,77^{\mathrm{NS}}$ \\
Épocas de avaliação (E) & 2 & $39.00^{* *}$ & $338,68^{* *}$ & $203,43^{* *}$ & $132,85^{* *}$ & $45,08^{* *}$ \\
Interação A x E & 8 & $0.12^{\mathrm{NS}}$ & $0,57^{\mathrm{NS}}$ & $1,46^{\mathrm{NS}}$ & $1,37^{\mathrm{NS}}$ & $0,67^{\mathrm{NS}}$ \\
\hline CV (a) & 12,6 & 17,9 & 31,7 & 41,4 & 19,3 \\
CV (b) & 1,4 & 1,7 & 3,9 & 5,9 & 2,3 \\
CV (c) & 2,8 & 3,0 & 5,0 & 2,3 & 3,9 \\
\hline
\end{tabular}

NS - Não-significativo.

*- Significativo a $5 \%$ pelo teste $\mathrm{F}$

** - Significativo a $1 \%$ pelo teste $\mathrm{F}$

de avaliação foi significativo ao nível de 1\%. Como não houve interação significativa entre os fatores adubação e épocas de avaliação, considerou-se apenas a média das três avaliações. O efeito das doses de matéria orgânica em todas as características avaliadas pode ser observado na Figura 1, sendo ajustado o modelo de regressão linear. Os resultados mostraram que estas características apresentaram aumento linear com o aumento das doses de esterco utilizadas, sendo a dose de $37,5 \mathrm{~kg}$ esterco planta $^{-1}$ a que proporcionou melhores resultados.

De acordo com as equações de regressão ajustadas, foi possível inferir que, para cada quilograma de esterco de curral curtido aplicado, houve um incremento na altura da planta, no diâmetro do caule, na circunferência, projeção e volume da copa de, respectivamente, $0,6844 \mathrm{~cm}, 0,1727 \mathrm{~cm}, 1,1327 \mathrm{~cm}, 5,8471 \mathrm{~m}^{2}$ e $5,8988 \mathrm{~m}^{3}$, sendo o volume da copa a característica que apresentou maior aumento com as doses mais elevadas de esterco de curral curtido.

Os efeitos do esterco de curral curtido nas características avaliadas foram mais evidentes na última avaliação, devido ao maior tempo para a mineralização da matéria orgânica, tornando os nutrientes mais disponíveis às plantas, com possíveis alterações nas características físicas, químicas e microbiológicas do solo. Somado a isso, as plantas foram enxertadas em Citrumelo Swingle, sendo reconhecido que as propriedades fisiológicas deste porta-enxerto retardam um maior desenvolvimento inicial das mesmas. Alterações na fertilidade do solo com a adição de matéria orgânica foram obtidas por Holanda et al. (1984), avaliando o efeito de doses crescentes de esterco de curral nas propriedades químicas do solo, após um ano da aplicação, obtendo um
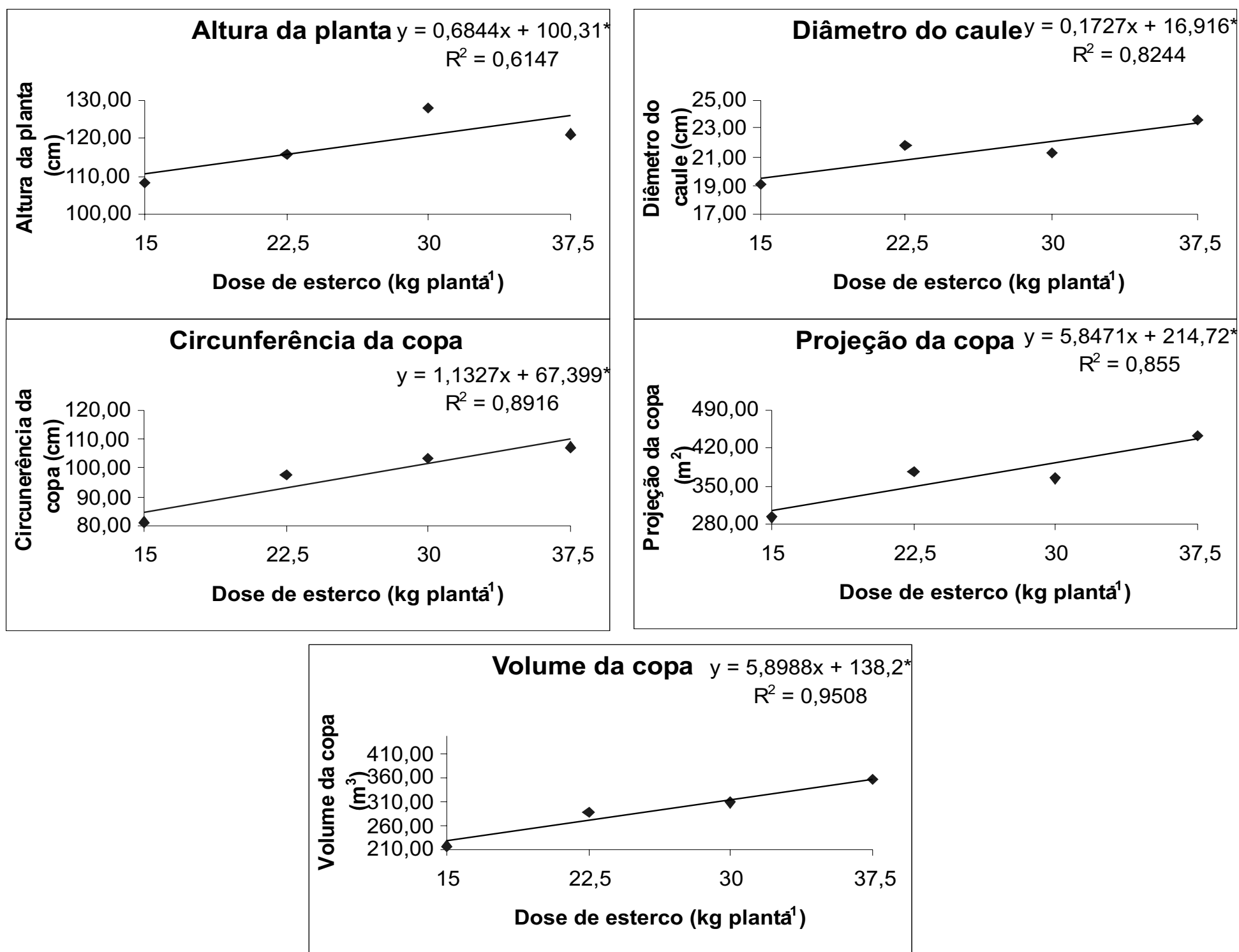

FIGURA 1 - Resultados médios das avaliações da altura da planta, diâmetro do caule, projeção, circunferência e volume da copa da tangerineira 'Poncã' submetida a níveis de esterco de curral. FCA/UNESP, Botucatu-SP, 2004. 
TABELA 5 - Resultados médios das três avaliações para altura das plantas, diâmetro do caule, projeção, volume e circunferência da copa de tangerineira 'Poncã' submetida a diferentes tratamentos com adubação química e orgânica. FCA/UNESP - Botucatu-SP, 2004.

\begin{tabular}{|c|c|c|c|c|c|}
\hline TRATAMENTOS & $\begin{array}{l}\text { Altura da planta } \\
(\mathrm{cm})\end{array}$ & $\begin{array}{l}\text { Diâmetro do caule } \\
(\mathrm{cm})\end{array}$ & $\begin{array}{l}\text { Circunferência da copa } \\
(\mathrm{cm})\end{array}$ & $\begin{array}{l}\text { Projeção da copa } \\
\left(\mathrm{m}^{2}\right)\end{array}$ & $\begin{array}{c}\text { Volume da copa } \\
\left(\mathrm{m}^{3}\right)\end{array}$ \\
\hline 800g SA planta ${ }^{-1}$ & 119,22 & 20,18 & 92,16 & 321,39 & 256,20 \\
\hline $15,0 \mathrm{~kg}$ esterco planta ${ }^{-1}$ & 108,11 & 19,11 & 80,81 & 292,21 & 216,54 \\
\hline $22,5 \mathrm{~kg}$ esterco planta ${ }^{-1}$ & 115,78 & 21,79 & 97,21 & 374,52 & 289,67 \\
\hline $30,0 \mathrm{~kg}$ esterco planta ${ }^{-1}$ & 128,11 & 21,31 & 103,47 & 364,28 & 308,10 \\
\hline $37,5 \mathrm{~kg}$ esterco planta ${ }^{-1}$ & 121,11 & 23,59 & 107,04 & 441,80 & 357,87 \\
\hline DMS & 20,28 & 5,17 & 25,32 & 173,30 & 161,15 \\
\hline
\end{tabular}

aumento linear nos valores de $\mathrm{pH}$ e nos teores de $\mathrm{P}, \mathrm{K}$ e $\mathrm{Ca}+\mathrm{Mg}$, e diminuição exponencial nos teores de alumínio trocável.

Utilizando o teste $\mathrm{t}$ de Dunnett, ao nível de 5\%, verificou-se que a dose de $15 \mathrm{~kg}_{\text {planta }}{ }^{-1}$ de esterco de curral, equivalente a $67 \%$ da dose de nitrogênio recomendada para a cultura, não diferiu estatisticamente do tratamento com o sulfato de amônio. As demais doses de esterco de curral curtido também foram semelhantes ao sulfato de amônio. Os resultados médios das três épocas de mensuração das características avaliadas são mostrados na Tabela 5. Tais resultados corroboram os obtidos por Cunha Sobrinho et al. (1975), quando avaliaram o efeito da adubação mineral comparada com a adubação orgânica em pomar de laranjeira 'Natal', sendo que, também, não obtiveram diferenças significativas no desenvolvimento das mudas nas medições efetuadas no primeiro ano após o plantio.

\section{CONCLUSÕES}

Os melhores resultados foram obtidos com a dose de $37,5 \mathrm{~kg}$ de esterco de curral planta ${ }^{-1}$, referente a $267 \mathrm{~g} \mathrm{~N}$ planta $^{-1}$, nas condições de solo descrito anteriormente. Com a referida dose, verificou-se maior crescimento e desenvolvimento das plantas. Para cada quilograma de esterco de curral curtido aplicado, houve um incremento na altura da planta, no diâmetro do caule, na circunferência, projeção e volume da copa. Os tratamentos com esterco de curral curtido não diferiram estatisticamente da adubação química realizada com sulfato de amônio.

\section{REFERÊNCIAS}

AGRIANUAL: anuário da agricultura brasileira. São Paulo: FNP Consultoria e Comércio, 2004. 376 p.

BOEIRA, R.C. et al. Adubação mineral e orgânica em porta-enxertos de citros. In: CONGRESSO BRASILEIRO DE FRUTICULTURA, 8., 1986, Brasília. Anais... Brasília: Sociedade Brasileira de Fruticultura e CNPq, 1986. p. 56.

BONILLA, J.A. Fundamentos da agricultura ecológica: sobrevivência e qualidade de vida. São Paulo: Nobel, 1992. 260p.

CARMO, M.S. et al. Componentes técnicos econômicos da agricultura orgânica comparados à agricultura convencional. In: CONFERÊNCIABRASILEIRADEAGRICULTURABIODINÂMICA, 2., 1996, Curitiba. Resumos... p.3.
CARVALHO, W.A. et al. Levantamento de solos da Fazenda Lageado Estação Experimental "Presidente Médici". Boletim Científico Faculdade de Ciências Agronômicas, Botucatu, v. 1, p.1-95, 1983.

CUNHA SOBRINHO, A.P. et al. Adubação mineral versus adubação orgânica em mudas de citros. In: CONGRESSO BRASILEIRO DE FRUTICULTURA, 3., 1975, Rio de Janeiro. Anais... Rio de Janeiro: Universidade Federal Rural do Rio de Janeiro., 1975. p. 59-60.

DE NEGRI, J.D. Citros. In: MANUAL técnico das culturas. 2.ed. Campinas: SAA/ CATI / DCT, 1997. p. 69-108.

HOLANDA, J.S. et al. Alterações na fertilidade de dois solos adubados com esterco de curral e cultivados com caupi. Revista Brasileira de Ciência do Solo, Viçosa, v.8, n. 3, p.301-304, 1984.

KIEHL, E.J. Fertilizante orgânicos. Piracicaba: Agronômica Ceres, 1985. 492p.

MALAVOLTA, E.; VIOLANTE NETTO, A. Nutrição mineral, calagem, gessagem e adubação dos citros. Piracicaba: Associação Brasileira para Pesquisa da Potassa e do Fosfato, 1989. 153p.

MOURÃO FILHO, F. de A. Efeito de diferentes porta-enxerto no vigor e produtividade das plantas e nas concentrações de macro e micronutrientes nas folhas de laranjeira Pêra (Citrus sinensis L. Osbeck). 1989. 189f. Dissertação (Mestrado em Horticultura) Faculdade de Ciências Agronômicas. Universidade Estadual Paulista, Botucatu, 1989.

PANZENHAGEN, N.V. et al. Respostas de tangerineiras 'Montegrina' à calagem e adubação orgânica e mineral. Pesquisa Agropecuária Brasileira, Brasília, v.34, n 4, p. 527 - 533, 1999.

PRADO, H. do. Solos do Brasil: gênese, morfologia, classificação, levantamento e manejo. Piracicaba: Ceres, 2003. 41p.

QUAGGIO, J.A.; RAIJ, B.V.; PIZZAJR. C.T. Frutíferas. In: RAIJ, B.V. et al. Recomendações de adubação e calagem para o Estado de São Paulo. 2. ed. Campinas: Instituto Agronômico e Fundação IAC, 1996. 217 p. (Boletim Técnico, 100).

SILVA, J.A.A. et al. Adubação Orgânica na cultura dos citros. SEMINÁRIO INTERNACIONAL DE CITROS - NUTRIÇÃO E ADUBAÇÃO, 4., 1996, Bebedouro. Anais... Campinas: Fundação Cargil, 1996. p. $211-236$.

TUBELIS,A.; SALIBE, A.A. Relações entre produção de laranjeira "Hamlin" e as precipitações mensais no altiplano de Botucatu. Pesquisa Agropecuária Brasileira, Brasília, v.24, n.7, p.801$806,1989$. 